\title{
HACIA UNA NUEVA RACIONALIDAD POLÍTICA A PARTIR DE LAS RELACIONES SOCIEDAD-ESTADO
}

\author{
A New Political Rationality Based on Society-State Relations \\ Jorge Balladares Burgos \\ Universidad Andina Simón Bolívar, Ecuador \\ jorge.balladares@uasb.edu.ec
}

\begin{abstract}
Resumen:
Hoy en día se percibe una crisis en torno a las relaciones de la sociedad con el estado producto del descrédito por no sentirse identificados con el gobierno de turno, los actos de corrupción, la ineficacia de las acciones en torno a desastres naturales y humanos como la pandemia del Covid-19. Esta realidad planetaria nos invita a pensar en una nueva racionalidad política que sea incluyente reconociendo las diferencias y diversidades del ciudadano común. Para este cometido, el presente artículo realiza una revisión de la literatura desde diferentes autores de la filosofía política sobre los sentidos y las tensiones en las relaciones entre la sociedad y el estado. Luego se plantea lo que es una nueva racionalidad política a partir de un sujeto político emergente que, ante las adversidades, las situaciones de marginalidad y pobreza, hace prevalecer el sentido de una conciencia colectiva. Desde un enfoque hermenéutico, se realiza una definición de lo político, como una forma alternativa de la praxis política que busca recuperar el sentido de organización, convivencia y toma de decisiones desde nuestra condición como seres políticos. De esta manera, las relaciones sociedad-estado serán resituadas para la búsqueda de un nuevo orden post-covid más justo, solidario, tolerante y resiliente.
\end{abstract}

\section{Palabras clave:}

Filosofía política, sociedad, Estado, política, racionalidad.

\begin{abstract}
:
Nowadays state-society relations are in crisis because citizens are not feeling identified with governments since acts of corruption and ineffective political actions around natural disasters such as the Covid-19 pandemic. This reality around the world leads us to think about new political rationality that could be inclusive, recognizing the differences and diversities of people. This article discusses literature review as a research methodology on the different meanings of state-society relations. Political rationality arises from an emerging political subject that, faces financial adversity, marginalization, and poverty as a common will. Based on the hermeneutics approach, a new concept of politics arises, as a political praxis whose
\end{abstract}


keywords are organization, coexistence, and decision-making from our human condition as political beings. Thus, state-society relations will be redefined to thrive in new post-covid normalcy based on values such as justice, solidarity, respect, and resilience.

\section{Keywords:}

Political Philosophy, Society, State, Politics, Rationality.

Recibido: 09/02/2021

Aceptado: 01/07/2021

\section{INTRODUCCIÓN}

Hoy en día se perciben relaciones tensas entre la sociedad y el Estado en varios países del mundo. Estas relaciones tensas marcan niveles de conflicto y tensión, Ilegando incluso al uso de la violencia como mecanismo de lucha por la legitimación de sus argumentos y puntos de vista sobre el destino político de una nación (Salazar, 1989). Las crisis sociales que han vivido varios países del mundo, la aparición de jóvenes y minorías descontentos con su gobierno por la falta de empleo y de oportunidades laborales, el endeudamiento de los estados nacionales a partir de la corrupción, entre otros, todos estos son manifestaciones contemporáneas de estas relaciones tensas entre la sociedad y el Estado, y que permite esbozar un nuevo ordenamiento en el planeta (Huntington, 1996). Esto ha originado un desgaste en la concepción de política que tiene el ciudadano común, y que la filosofía puede ayudar a re-significar el sentido de la política desde el concepto de lo Político, como aquella dimensión propia del ser humano que busca la organización y la convivencia social.

El presente artículo realiza un recorrido histórico desde la historia de la filosofía de las relaciones Sociedad-Estado. Asimismo, se revisa el planteamiento de esta relación desde algunos autores de la filosofía occidental y del pensamiento latinoamericano, para llegar a un nuevo concepto de la política que sea más inclusiva, dialógica y busque el bien común de sus ciudadanos (Scannone, 1990; Roig, 1981). A través de este recorrido histórico, se irán dilucidando elementos para un concepto de lo político, como una forma de ejercer la política por parte de los ciudadanos sin necesidad de la mediación de un partido político oficial.

Ricoeur (1986) se refiere a la política en la civilización planetaria o universal como una política racional. Él considera que a través de la experiencia de los diversos regímenes políticos alrededor del mundo se repite una experiencia de una técnica política única. El Estado moderno posee en sí una estructura política universal discernible, en la que se incluye la burocracia y la tecnocracia, y por ende, ellas son expresiones de esta racionalidad política común. La experiencia política única de la humanidad hoy se traduce en la búsqueda de la democracia, en la consecución del bienestar y la cultura y en la necesidad de una organización. La administración en los Estados nacionales modernos es una expresión de racionalización del poder que se 
compone muchas veces de un cuerpo de funcionarios que preparan decisiones y las ejecutan sin ser ellos mismos responsables de la decisión política (Balladares, 2014).

Esta manera impersonal de la administración en la política ha producido en la conciencia colectiva un descrédito, tanto en la función pública como en las instituciones estatales. Por ende, el ejercicio de la administración política puede convertirse en ocupar un cargo o puesto, en ser parte de una burocracia dorada, en tener la posibilidad de mejorar un ingreso, entre otros. Por esta razón, la gente hoy en día, no cree en los funcionarios públicos ni en los políticos dada su poca efectividad del ejercicio político a favor del pueblo. Esta racionalidad política, como la llama Ricoeur, nos ha llevado a considerar un ejercicio técnico-instrumental de la política en sí, en des-mérito de una democracia de base, de un ejercicio político cotidiano, de la voluntad del pueblo.

Por esta razón, creo que es necesario reivindicar la política a través de lo Político (Balladares, 2006). Recuperar espacios de participación ciudadana, promover organizaciones democráticas de base, construir una cultura ciudadana y de participación política activa, educar a las nuevas generaciones en una conciencia de nación, todo ello son algunos de los desafíos que nos presenta el ámbito de lo Político para una recuperación del verdadero significado de la praxis política. Frente al descrédito y desencanto del ejercicio de la política, lo Político se constituye un camino legítimo para recuperar su validez.

Por otro lado, lo político también puede ser reivindicado en espacios transnacionales, donde los diferentes Estados nacionales se pueden comprometer en procesos de cooperación política en términos cosmopolitas. Asimismo, se tendría que hablar de los movimientos sociales y las organizaciones sociales como miembros activos de una sociedad civil que trascienden las fronteras nacionales y que pueden tener una repercusión en lo político de los países, basados en nuevas formas de integración social y de solidaridad universal (Balladares, 2014; Habermas, 2000).

En este itinerario de filosofía política voy a realizar una aproximación en los términos política y Político, para poder delimitar el ámbito de estas dos realidades de la praxis política. Para este cometido, se hace necesario realizar un recorrido histórico de lo Político a través de la tradición filosófica y de algunos autores del pensamiento latinoamericano. Luego, a partir del reconocimiento de un sujeto político emergente entraremos a realizar una revalorización del ámbito de lo Político como una alternativa para recuperar aquellos espacios de actividad política tan en descrédito dentro de las conciencias de los colectivos nacionales, y por ende, llegar a replantear algunos desafíos.

\section{LAS RELACIONES SOCIEDAD-ESTADO EN LA TRADICIÓN FILOSÓFICA}

En La República de Platón (2000) existe una preocupación por encontrar el origen de la polis, y este autor plantea una subsistencia a través de una organización social que busca la perfección y el bien público. Desde la necesidad de juntarse para formar una sociedad o polis -que a medida que va creciendo necesita una organización social que le permite sostenerse a través de los artesanos y agricultores, defenderse de sus enemigos a través de los militares, y gobernarse a través de los magistrados y jefes- se 
Ilegará al planteamiento de un Estado. No obstante, quienes gobernarán este Estado tendrán características de filósofos o personas que buscan la verdad y el bien común a través de las ideas y el mundo de lo inteligible (Apel, 1991).

A mi modo de ver, Platón se preocupa por encontrar los orígenes de la organización civil, y busca el camino de realización y perfección de las sociedades a través de una idea de bien. Aunque no creo que se logra dilucidar todavía un conflicto Sociedad-Estado en cuanto tal, en el concepto de polis se pueden encontrar elementos iniciales de lo Político, como organización civil y bien común. De hecho, hay una organización y una forma de ser diferente a la del gobierno que parte del ciudadano común, que se manifiesta en la vida cotidiana y que busca un bien para todos. El ámbito de lo Político que quiero definir en este trabajo parte de las necesidades de la gente, del interés por satisfacer aquellas que el Estado no lo puede hacer y que la misma sociedad civil se organiza y se junta para encontrar caminos de solución.

En la Política de Aristóteles (1988) aparecen más diferenciados los conceptos de Sociedad y Estado. A raíz de las diferentes asociaciones y las sociedades naturales (familia y aldea), Aristóteles plantea una comunidad política o ciudad, en la que los elementos materiales estarán unificados y regidos por la forma de gobierno que le corresponda. A través del concepto aristotélico del hombre como ser político, se puede recuperar aquella dimensión antropológica del ser humano que implica la organización, la convivencia, las relaciones y la comunicación. Ser políticos no tiene una relación exclusiva con el ejercicio de la política en sí, sino que nos invita a considerar aquella dimensión de la vida cotidiana donde los seres humanos se organizan, intercambian ideas para el bien común, socializan y se relacionan entre todos, comunican opiniones y sentimientos, etc.

Dentro de una perspectiva filosófico-teológica medieval del poder político, hay que considerar la teoría política de Santo Tomás, que de alguna manera, retoma la perspectiva de Aristóteles al considerar al hombre como un ser político y social a la vez (Hirschberger, 1979). El Aquinate considerará al ser humano como un animal naturalmente social con razón (ratio), que le proporciona su capacidad para vivir con otro y le da el principio de semejanza con Dios. Santo Tomás reconoce la potestad del pueblo para poner y quitar gobernantes, para decidir su futuro eligiendo la persona más idónea para el gobierno, a diferencia de San Agustín de Hipona que tiene una visión absoluta del gobernante como el elegido de Dios. En este sentido, Tomás de Aquino nos propone una racionalidad de lo Político, donde las relaciones interpersonales y sociales estarán marcadas por la lógica de la razón y del sentido común.

En esta línea de continuidad aristotélico-tomista, quisiera mencionar el avance que realiza Francisco Suárez. Este autor reconoce el origen de la comunidad a partir de las diferentes sociedades naturales que son perfectas en sí, pero que no logran tener un objetivo en la política en sí. Sin embargo, este autor se pregunta sobre la potestad de la comunidad política, si viene de Dios o de los hombres, y con qué poder se puede regir a un Estado. Suárez responderá a este problema con una visión hilemórfica: Dios da la forma de gobierno en la materia del cuerpo político organizado en el Estado. Aplicando esta tesis de Francisco Suárez a la política y a lo Político, se puede decir que uno de los objetivos de este trabajo es encontrar de qué 
manera lo Político llevará a una praxis renovada de la política, cómo lo Político puede transformar una política desgastada, deforme y cuya realidad material necesita de una transformación intrínseca (Hirschberger, 1979).

En la época del pensamiento político moderno se puede dilucidar de manera explícita el conflicto Sociedad-Estado. Nicolás Maquiavelo, en su obra El Príncipe, presenta una metodología de gobierno, una receta para el ejercicio del poder, un instructivo de cómo se debe gobernar y mantenerse en el poder. Sin embargo, Maquiavelo nos aporta un dato que rompe con la tradición clásica-medieval: él considera que los seres humanos son de naturaleza mala y egoísta, de ambición limitada. A partir de esta realidad, la relación Sociedad-Estado pasa por un conflicto, por una lucha de poderes entre el pueblo y los gobernantes, en el que el Estado pasa a ser el instrumento poderoso para frenar el deseo egoísta de los hombres de la sociedad. Lo Político cuestiona y reacciona frente a la inercia, injusticias y atropellos de las políticas estatales y de sus gobernantes (Maquiavelo, 1999).

Thomas Hobbes profundiza la realidad del conflicto entre los seres humanos, que según este autor, son egoístas y competitivos. Para superar el conflicto, es necesario lograr un pacto entre los individuos. En el pensamiento hobbesiano podemos descubrir elementos de lo Político, cuando se reconoce que entre los seres humanos hay una necesidad imperiosa de asociarse y lograr pactos para evitar conflictos y desacuerdos que pueden llevar a desintegraciones sociales. Frente a esta necesidad de pactar y lograr acuerdos, surge la creación del Estado con un gobernante cuyo papel consistirá en la conservación del ser humano, y en la regulación de los deseos y competencias individuales.

Sin embargo, la postura hobbesiana del gobernante absoluto basado en una mayoría resulta ser contradictorio con la concepción de lo Político que aquí intentamos construir. La realidad actual nos demuestra que nuestras formas democráticas han puesto a gobernantes que de hecho no representan una mayoría absoluta, o al menos, aparentan ser ganadores de elecciones por mayoría. La visión que intento dar sobre el ámbito de lo Político lleva justamente a des-absolutizar a los gobernantes y a buscar espacios políticos alternativos del ejercicio del poder. Más aún, Hobbes menciona que el Estado tiene una aceptación resignada por parte de los individuos, ante la posibilidad de una amenaza de guerra perpetua; ante esta realidad de considerar la necesidad un poder político como mal menor, ésta se refleja en las conciencias de los grandes colectivos de los países en las que aceptan los vaivenes de la política con resignación, que miran desde la distancia cómo los políticos de turno prometen y no cumplen (Hobbes, 2002).

Jean Jacques Rousseau, en su obra El contrato social, se pregunta dónde está la fuente de autoridad legítima en el Estado, y responde que ella está en el contrato del pueblo con el soberano. El pueblo tiene la potestad de revocar en cualquier momento ese poder. Ante esto, Rousseau planteará la voluntad general como normativa del contrato social. La voluntad general es definida como una fuerza que se expresa por la mayoría por la finalidad del bien común. Esta voluntad descansa en el pueblo y es expresión de derecho sagrado, entendido lo sagrado como aquella socialidad en que los hombres están reunidos soberanamente. Esta voluntad general rousseauniana es uno de los elementos de lo Político, ya que en este ámbito conviven las ideas y los 
sentimientos de cada uno de los ciudadanos de una nación. Lo Político, a través de la voluntad de todos, legitimará o des-legitimará el ejercicio de los gobernantes y los partidos políticos (Rousseau, 2000).

\section{HACIA UNA NUEVA RACIONALIDAD POLÍTICA}

Se reconoce un nuevo tipo de racionalidad mediadora, una racionalidad políticoemergente que reconoce lo suyo y lo adveniente y los transforma. La racionalidad político-emergente -como la llamaré aquí- abre un nuevo tipo de unidad cultural y política para nuestros países en la comunión de los diferentes (Farrell et.al, 1996). Scannone hace mención de una racionalidad promotora de una dinámica comunitaria fundamentada en el diálogo y dialogando con otras comunidades vivas, dándose al mismo tiempo la unidad y la diferencia. Ella abre un espacio compartido e interdiscursivo donde, más allá de hablar de una diferencia que puede caer en una simple diferencia en cuanto tal, habría que reconocer la particularidad, la cual constituye la identidad cultural de una comunidad humana determinada (Balladares, 2013; Scannone, 1990).

Para lograr este inter-diálogo es fundamental no pre-sub-poner que todos tenemos el mismo nivel de comunicación, ya que partimos de diversas raíces culturales. De esta manera, la comunicación y la comunión de la nueva racionalidad políticoemergente nos puede llevar a replantear la democracia como forma de gobierno de todos, por todos y para todos, y no delegada a unos pocos. Además, la razón humana no entra solamente a formar una comunidad de particularidades de manera abstracta o metafísica, sino que ella es partícipe de un proceso histórico de mutuo enriquecimiento continuo. Esto lo podemos Ilamar transculturación, proceso en el cual transportamos nuestras tradiciones y dejamos que nos influyan otras. Pasamos de este modo a ser emisores de nuestra identidad y receptores de otras particularidades en un verdadero proceso de universalización (Fornet-Betancourt, 1994; Habermas, 1990).

En este itinerario especulativo hemos llegado a un punto en el que nos preguntamos de qué manera el sujeto político emergente es protagonista de la historia. Para ello, se parte de una noción de probabilidad emergente como la realización sucesiva de posibilidades en situaciones concretas de acuerdo a sus probabilidades. Esta noción que basa la complementariedad de las investigaciones clásicas y estadísticas se da en el sujeto, pero además tenemos que considerar su contexto, su historicidad y libertad. Una probabilidad emergente permite que el hombre y la mujer, como sujetos de la historia, sean responsables de que los mecanismos estructurales no se autonomicen y se absoluticen. El ser humano irá descubriendo nuevos eventos emergentes posibles, siempre y cuando estén condicionados por lo ético, político, cultural y religioso, y no solamente lo natural, lo tecnológico y lo estrictamente económico (Scannone et at., 1995; Crowe \& Doran, 1992).

Este sujeto que se constituye permite que la sociedad civil emergente vaya siendo, se construya. Una probabilidad emergente posibilita el surgimiento de nuevas identidades y el reconocimiento de las diferencias -la identidad se va construyendomás que ser un hecho dado de antemano. Este sujeto emergente es político al ser constructor de la política a través de una praxis ética e histórica (Cortina, 1997). 
Entonces se puede decir que el actual desafío del sujeto político-emergente consiste, en primer lugar, en lograr una síntesis vital transformadora entre su herencia cultural humana y lo válido del progreso, de la sociedad y de la cultura adveniente. Esta síntesis transformadora ha de ser creativa, sin que sea una copia de modelos externos que no respondan a la propia idiosincrasia cultural y al sentido humano. En segundo lugar, el sujeto político-emergente, como protagonista de su praxis política, busca una actitud vital de discernimiento ante lo bueno y las contradicciones de lo ajeno y de lo propio.

Este sujeto responde a su cultura desde su cultura: este sujeto, como protagonista y actor, adopta, resiste y transforma en todo nivel (social, económico, político, religioso, educativo, cultural) lo suyo y lo extraño para sí. Todo esto nos lleva a pensar en un nuevo humanismo cuyas características sean la integración, gratuidad, creatividad, participación, libertad, comunión, diálogo, comunicación, afecto por lo nuestro, consentimiento, concertación, que lleven a una nueva comprensión del ser humano en torno a la política y a lo Político (Balladares, 2014; Levinas, 1979).

Pero muchas veces el sujeto político-emergente tiene que enfrentarse y decidir frente a las situaciones límites de pobreza y de injusticia, cuya causa la encontramos en los modelos estructurales anclados por años en las diferentes sociedades (Rousseau, 1997). Su capacidad de re-vivir frente a situaciones de muerte lo llevan a luchar contra las amenazas, y a su vez, a buscar respuestas alternativas desde su idiosincrasia propia. La humanidad tiene como desafío buscar sus fuentes y raíces para mirar el futuro. Pero este sujeto no está solo, y como respuesta a las adversidades, hay que recuperar aquella experiencia de la palabra nosotros como conciencia colectiva, para comprender el carácter de colectividad del sujeto político emergente.

De hecho, no es fácil diferenciar o encontrar un límite entre la política y lo político. Aunque estos términos se los relaciona con los asuntos de gobierno o Estado como primera percepción, no obstante, es necesario recuperar el sentido de lo político en la vida diaria, en las relaciones sociales y familiares, en la conciencia y voluntad ciudadanas, en las formas cotidianas y locales de organización. Lo político se constituye como aquella dimensión vital que empodera a decidir sobre asuntos de la vida social, e inclusive permite legitimar o alterar la normatividad y moralidad que rige la convivencia humana, desde una perspectiva aristotélica donde el ser humano es un sujeto político. Lo político, a diferencia de la política en sí, corresponde a un imaginario de política no-formal o a-política. De esta manera, la política pragmática se complementará con lo político, y a su vez, será su fuente para una praxis política que busque el bien común y un bien-estar (Echeverría, 2002; Dussel, 1986).

La categoría de lo político se construye en el encuentro interpersonal, en la interacción y el diálogo. Las relaciones interpersonales, la convivencia y el intercambio de ideas son escenarios idóneos para una manifestación de lo político. Este nuevo ámbito categorial permite fomentar las relaciones y los encuentros entre los diferentes ciudadanos, actores sociales, organizaciones, colectivos, grupos y movimientos sociales. Lo político promueve los debates, las discusiones, los disensos, los consensos, las negociaciones y las concertaciones necesarias para la organización y la convivencia (Balladares, 2006). 
Lo político es el espacio donde se funda y altera la legalidad que condiciona la convivencia humana, permite adentrarnos al lado ético de lo Político. De alguna manera, este espacio reformador de lo vigente, de lo establecido, se puede volver $i$ legal o a-legal para quienes mantienen el poder político y quienes realizan una praxis política. Una ilegalidad para una legalidad moral y vigente del poder dominante se vuelve legal desde el punto de vista de los marginados y excluidos. La legalidad de la ley puede ser injusta en otros contextos y puede no ser criterio absoluto de bondad y justicia. Por ende, es importante que lo legal tenga una perspectiva ética y comunidad, basada en una perspectiva de tolerancia, justicia y solidad (Rawls, 2000; Scannone \& Santuc, 1999; Arendt, 1993, Ellacuría \& Scannone, 1991; Dussel, 1986; Scannone, 1984).

Lo público puede ser definido como el espacio de interés de las personas, en contraposición con definiciones que identifican lo público como lo masivo. Este espacio implica el bien común, donde todos buscan un interés colectivo, cada uno desde su respectivo ámbito familiar, laboral, social, entre otros (Sen 2000; Savater 1992; Weber, 1976; Prieto, 1994; Alfaro, 1994). Existe un carácter de oposición interna en la esencia de lo político cuando se percibe una dualidad conflictiva o dicotómica. Así como se puede hablar del bien y del mal en lo ético, de lo bello y lo feo en lo estético, de lucrativo y no-lucrativo en lo económico, también en lo político se pueden identificar categorías dicotómicas como amigo y enemigo, aliado y noaliado. Esta dicotomía en lo político se constituye en su aspecto antagónico en la lucha de poderes y espacios o territorialidades en su seno. De esta manera, se puede reconocer la lucha cotidiana de poderes y espacios entre los miembros de una familia, en la discusión en torno a las ideas políticas entre los ciudadanos, los debates en torno a acciones por parte de los movimientos sociales, los colectivos y las organizaciones. Esta dicotomía permite establecer una tensión relacional en el seno de lo político, que a su vez, requiere del diálogo, los acuerdos y los consensos mínimos para la toma de decisiones, una convivencia armónica y la consecución de metas u objetivos (Giddens, 1997; Schmitt, 1994).

\section{CONCLUSIONES}

En América Latina y en el mundo en general surgen nuevas manifestaciones de lo Político a partir de la emergencia de la sociedad civil y sus diferentes actores. La pandemia del Covid-19 ha evidenciado un desencanto de sus ciudadanos por la gestión de los gobiernos de turno, y de la no-identificación con el ciudadano común con sus autoridades y políticos. Frente a este desánimo y desconocimiento de una praxis política viciada, aparecen sectores de la sociedad civil, organizaciones no gubernamentales, líderes desde las bases, jóvenes preocupados por el futuro de sus países, el internet y las redes sociales, entre otros, que buscan espacios de participación, empoderamiento y de presencialidad (Scannone \& Santuc, 1994; Weil, 1982).

Por este motivo, es importante, re-valorizar la dimensión humana de la politicidad, que permite identificar aquellos rasgos intrínsecos de la organización, socialización, civilidad, confrontación y consenso en la experiencia de los seres humanos. Una nueva racionalidad política, definida como lo Político a partir de las relaciones 
Sociedad-Estado en la historia de la filosofía política, permite encontrar nuevos sentidos para una nueva praxis política. Po este motivo, urge una nueva racionalidad política planetaria y local que replantee el ejercicio de la política en sí para re-orientar el arte de gobernar de nuestros pueblos.

En este sentido, una nueva racionalidad política a través del sentido de lo político puede llevar a encontrar un nuevo punto de equilibro en las relaciones de la sociedad con el estado, donde la sociedad se sienta representada y escuchadas por los gobiernos de turno, y a su vez, el estado sea sensible a las necesidades, demandas, pensar y sentir de los ciudadanos comunes. Esta realidad planetaria post-covid invita a pensar en una nueva racionalidad política que sea incluyente reconociendo las diferencias y diversidades del ciudadano común.

Se puede inferir que, a lo largo de la historia de la filosofía y el pensamiento occidental, las relaciones sociedad-estado han sido tensas, en varios episodios conflictivas, y en otros, conciliadoras y armónicas. No obstante, la crisis planetaria producto del covid-19 invita a pensar y avizorar un nuevo orden planetario donde la nueva normalidad implique una alianza estratégica entre las sociedades y los gobiernos de turno. Es necesario replantear que las libertades individuales son superadas en el llamado de una solidaridad planetaria cuando se requiere el esfuerzo colectivo para enfrentar futuras amenazas externas, como desastres naturales, catástrofes o pandemias.

Ante la crisis de descrédito de las acciones tomadas por los gobiernos de turno frente a la pandemia por parte de sus conciudadanos, es necesario re-legitimar y fortalecer el papel del Estado como mediador entre el individuo y la sociedad, como garante del bien público y del bienestar. Esta re-legimitación estará encaminada a que las autoridades de turno sean sensibles a las necesidades del ciudadano común. En este momento histórico de la humanidad, es importante el esfuerzo mancomunado de cada individuo, de las sociedades y los diferentes estados para encontrar las estrategias efectivas para enfrentar los desafíos del presente y del futuro. Además de las amenazas externas a enfrentar, es importante buscar un nuevo orden planetario que privilegia la justicia ante las brechas socio-económicas, la solidaridad ante el individualismo exacerbado, la tolerancia hacia la diversidad y las diferencias, y la resiliencia ante situaciones emergentes. Estos próximos retos desafían a la humanidad presente a dejar un mundo en mejores condiciones para la humanidad futura.

\section{REFERENCIAS}

ALFARO, R.M. (1994). La interlocución radiofónica. Quito: OCLACC.

APEL, K.O. (1991). Teoría de la verdad y ética del discurso. Barcelona: Paidós.

ARENDT, H. (1993). La condición humana. Barcelona: Paidós.

BALLADARES, J. (2006). Lo Político. Una revalorización para la política en América Latina. Quito: Educom. 
BALLADARES, J. (2014). Hacia una nueva conceptualización de lo Político. Nuevo Pensamiento: Revista de Filosofía, 4 (4), Argentina: Instituto de investigaciones filosóficas de la Facultad de Filosofía de la Universidad del Salvador, área San Miguel. https://bit.ly/2n2Twp6

BALLADARES, J. (2013). Una racionalidad emergente en la educación. Revista Sophia: Colección de Filosofía de la Educación, 14, Quito: Editorial Universitaria Abya-Yala. https://bit.ly/2nw4rrK

CORTINA, A. (1997). Ciudadanos del mundo. Madrid: Alianza Editorial.

CORTINA, A. (1995). Ética civil y religión. Madrid: PPC.

CROWE, F. y DORAN, R. (ed.) (1992). Collected works of Bernard Lonergan III. University of Toronto Press.

ECHEVERRÍA, B. (2000). Las ilusiones de la Modernidad. Quito: Tramasocial.

ELLACURÍA, I., y SCANNONE, J.C.(comp.) (1992). Para una filosofía desde América Latina. Bogotá: Indo-American Press Service.

FARRELL, G., GARCIA, D., et al. (1996). Argentina, tiempo de cambios. Buenos Aires: San Pablo.

FORNET-BETANCOURT, R. (1994). Filosofía intercultural. Universidad Pontificia

de México.

GIDDENS, A, (1997). Política, sociología y teoría social: reflexiones sobre el pensamiento social clásico y contemporáneo. Barcelona: Paidós.

HABERMAS, J. (2000). La constelación posnacional. Ensayos políticos. Barcelona: Paidós.

HABERMAS, J. (1990). Teoría de la acción comunicativa, Madrid: Taurus.

HEGEL, G. (1966a). Fenomenología del Espíritu. México D.F.: Fondo de Cultura Económica.

HEGEL, G. (1966b). Principios de la Filosofía del Derecho. México D.F.: Fondo de Cultura Económica.

HIRSCHBERGER, J. (1979). Historia de la Filosofía, v. 1, Barcelona: Herder.

HUNTINGTON, S. (1996). El choque de civilizaciones y la reconfiguración del orden Mundial. Barcelona: Paidós.

LEVINAS, E. (1974). Humanismo del otro hombre. México D.F.: Siglo XXI.

MAQUIAVELO, N. (1999). El Príncipe y otros escritos. Bogotá: Ediciones Universales.

PLATÓN (2000). Obras Selectas. Madrid: Edimat.

PRIETO, D. (1994). La vida cotidiana, fuente de producción radiofónica. Quito: OCLACC. 
RAWLS, J. (2000). Teoría de la justicia. México D.F.: Fondo de Cultura Económica, 2000.

RICOEUR, P. (1986). Ética y cultura. Buenos Aires: Docencia.

ROIG, A. (1981). Teoría y crítica del Pensamiento Latinoamericano. México D.F.: Fondo de Cultura Económica.

ROUSSEAU, J. (1997). El origen de la desigualdad. México D.F.: Fondo de Cultura Económica, 1997.

ROUSSEAU, J. (2000). Obras selectas. Madrid: Edimat.

SALAZAR, Franklin, Cultura, subcultura y violencia, Quito, PUCE, 1989.

SAVATER, F. (1992). Política para Amador. Barcelona: Ariel.

SCANNONE, J.C. (1990). Un nuevo punto de partida en la filosofía latinoamericana. Buenos Aires: Guadalupe.

SCANNONE, J.C. (1984). Sabiduría popular, símbolo y filosofía. Buenos Aires: Guadalupe.

SCANNONE, J.C., AQUINO, M. de, y REMOLINA, G. (comp.) (1995). Hombre y sociedad, reflexiones filosóficas desde América Latina. Bogotá: Indo-american Press Service.

SCANNONE, J.C., y PERINE, M. (comp.) (1994). Irrupción del pobre y quehacer Filosófico. Buenos Aires: Bonum.

SCANNONE, J.C., y REMOLINA, G., (comp.) (1998). G., Ética y Economía. Buenos Aires: Bonum.

SCANNONE, J.C., y SANTUC, V. (comp.) (1999). Lo político en América Latina. Buenos Aires: Bonum.

SEIBOLD, J. (1983). Pueblo y saber en la fenomenología del espíritu de Hegel. San Miguel, Argentina: Universidad del Salvador.

SEN, A. (2001). Desarrollo y libertad. Bogotá: Planeta, 2001.

WEBER, M. (1976). Economía y sociedad. Tubinga: Mohr Siebeck Verlag.

WEIL, E. (1982). Philosophie et réalité. Paris: Ed. Beauchesne.

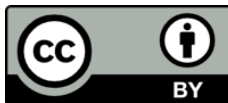

